\title{
Lithium Intoxication-Induced Myxedema Coma in a Schizophrenic Patient: A Case Report
}

\author{
Sonny Cruz, Lermah Bunoy \\ Department of Internal Medicine, World Citi Medical Center, Quezon City, Philippines \\ Email: sybcruz@gmail.com
}

How to cite this paper: Cruz, S. and Bunoy, L. (2021) Lithium Intoxication-Induced Myxedema Coma in a Schizophrenic Patient: A Case Report. Open Access Library Journal, 8: e8162.

https://doi.org/10.4236/oalib.1108162

Received: November 7, 2021

Accepted: December 7, 2021

Published: December 10, 2021

Copyright $\odot 2021$ by author(s) and Open Access Library Inc.

This work is licensed under the Creative Commons Attribution International License (CC BY 4.0).

http://creativecommons.org/licenses/by/4.0/

(c) (i) Open Access

\begin{abstract}
Lithium intoxication-induced myxedema coma, is a rare, life threatening \& emergency presentation of severe hypothyroidism, it can be easily misdiagnosed in patients with unknown history of hypothyroidism. Studies have shown that Lithium mechanism on thyroid is that it inhibits synthesis \& release of thyroid hormones. This case report describes a 59-year old patient with schizophrenia admitted with lithium intoxication \& myxedema crisis. This case emphasizes the fact that severe \& dangerous hypothyroidism can develop in some patients who take lithium for prolonged period. A 59-year-old female was admitted to our institution with history of tremors \& a decrease in level of consciousness. Patient was a known case of Type 2 Diabetes Mellitus \& Schizophrenia, on Insulin, Olanzapine \& Lithium. On examination patient is hypothermic, bradycardic, with periorbital puffiness, non-pitting edema on lower extremities \& tremors on all extremities. Thyroid function tests showed primary hypothyroidism. The serum lithium level was moderately elevated. She was initially managed with Levothyroxine started $100 \mathrm{mcg} / \mathrm{tab}$ once a day before breakfast \& was increased to $150 \mathrm{mcg} / \mathrm{tab}$ daily as home medication. Liothyronine $25 \mathrm{mcg} / \mathrm{tab}, 1 / 2 \mathrm{tab}$ Q8, Hydrocortisone $50 \mathrm{mg} / \mathrm{IV}$ Q8, IV antibiotics \& IV fluids were also given. Lithium was discontinued. On the fourth hospital day patient was transferred to ICU due to a decrease in sensorium \& close monitoring. From day ten, patient started showing progressive improvement $\&$ by day fourteen, patient was discharged. In conclusion lithium-induced hypothyroidism may be life-threatening, if myxedema crisis is suspected treatment should be initiated even without the laboratory tests. It is recommended that periodic thyroid function should be monitored before \& during lithium therapy \& drug should be discontinued \& appropriate therapy instituted if hypothyroidism develops.
\end{abstract}

\section{Subject Areas}

Internal Medicine 


\section{Keywords}

Myxedema, Lithium, Schizophrenia, Hypothyroidism

\section{Introduction}

Lithium intoxication-induced myxedema coma, is a rare, life threatening \& emergency presentation of severe hypothyroidism, can be easily misdiagnosed in patients with unknown history of hypothyroidism. Lithium treatment is reported to cause hypothyroidism in $20 \%$ \& goiter in $40 \%$ of recipients [1].

Lithium is very potent drug commonly used for treatment of bipolar disorder. It has multiple effects on thyroid function, including inhibition of thyroid hormone release, effects on the hypothalamic pituitary axis, \& effects on the thyroid autoimmunity. Lithium is concentrated in brain \& thyroid where it may reach levels 4 times that of plasma. The most important effect of lithium is inhibition of thyroid hormone release from thyroid gland by alteration in tubulin polymerization \& inhibition of TSH action on cyclic adenosine monophosphate (cAMP) [2].

Myxedema coma is defined as severe hypothyroidism leading to decreased mental status, hypothermia, \& other symptoms related to slowing of function in multiple organs. It can occur in severe, longstanding hypothyroidism, particularly chronic autoimmune thyroiditis. Myxedema coma can also occur in patients with central hypothyroidism, lithium-induced hypothyroidism, pembrolizumab-induced hypothyroidism \& some cases in patients taking amiodarone.

This case report describes a 59-year old patient with schizophrenia admitted with lithium intoxication \& myxedema crisis. This case emphasizes the fact that severe \& dangerous hypothyroidism can develop in some patients who take lithium for prolonged period. The aim of this study is to present a case of a schizophrenic patient with lithium-induced myxedema coma.

\section{Case Synopsis}

This is case of a 59-year-old female who initially presented with tremors. History started, one day prior to consult, patient experienced postural tremors associated with difficulty of ambulation. No chest pain, agitation, difficulty of breathing, vomiting noted. Few hours, prior to consult patient was seen lying on the floor with blank stare $\&$ still with tremors. Patient was immediately brought to nearby hospital, diagnosed with community acquired pneumonia \& lithium intoxication. Advised admission but opted to transfer in our institution hence subsequent admission.

Patient is a diagnosed case of Schizophrenia for more than 10 years, maintained on Olanzapine $10 \mathrm{mg} / \mathrm{tab} \&$ Lithium $450 \mathrm{mg} /$ tablet OD claims to have 
good compliance but loss to follow up since 2017. Patient also has Type 2 Diabetes Mellitus, controlled on Insulin glargine $10 \mathrm{u}$ SQ daily \& Pioglitazone 15 $\mathrm{mg}+$ Metformin $500 \mathrm{mg} / \mathrm{tab}$ once a daily.

On examination patient is hypothermic, bradycardic, noted to have dry skin \& buccal mucosa, periorbital puffiness \& with non-pitting edema on lower extremities. Metabolic work up were requested, which showed leukocytosis with neutrophilic in predominance, and an elevated HbA1C (see Table 1).

On the day of admission, patient was started on Ceftriaxone $2 \mathrm{~g}$ IV once a day \& Azithromycin $500 \mathrm{mg} / \mathrm{tab}$ once a day for management of community acquired pneumonia. Initial impression is community acquired pneumonia \& lithium toxicity. CBG monitoring was done. Patient was referred to Neurology \& Psychiatry service for further evaluation \& management, Lithium tablet was discontinued.

On the third hospital day, thyroid function tests showed primary hypothyroidism. The serum lithium level was moderately elevated (see Table 2). Patient was then started on Levothyroxine $100 \mathrm{mcg}$ once day before breakfast. Patient was referred to Endocrinology service for management of hypothyroidism \& diabetes. Insulin glargine was increased, CBG monitoring was continued.

On fourth hospital day, patient was somnolent \& stuporous. Patient was intubated due to decreased in sensorium \& transferred to ICU for close monitoring. Plain cranial CT scan was done which showed no evidence of intracranial hemorrhage or infarct at the time of study. Working impression was lithium induced hypothyroidism leading to myxedema coma, hence stat dose of levothyroxine $100 \mathrm{mcg} / \mathrm{tab} \&$ Liothyronine (Cytomel) $25 \mathrm{mcg} / \mathrm{tab} 1 / 2$ tab Q8, Hydrocortisone $50 \mathrm{mg} / \mathrm{IV}$ Q8 were ordered.

During the stay in the ICU, patient had episode of blood pressure elevation, pulmonary congestion \& CBG elevation which was then controlled, consequently patient was extubated, noted progressive improvement $\&$ was transferred to a regular room.

On the tenth to fourteenth hospital day, patient had stable vital signs, IV antibiotics were shifted to oral, CBG was controlled, started on Vildagliptin $50 \mathrm{mg} / \mathrm{tab}$ twice a day, Insulin Glargine $30 \mathrm{u}$ SQ once day. Levothyroxine $150 \mathrm{mcg} / \mathrm{tab}$ OD was given as home medication. Patient was discharged.

\section{Discussion}

This is a case of a schizophrenic patient who presented with severe hypothyroidism in a background of lithium intoxication. Extreme manifestation of hypothyroidism is called myxedema coma or myxedema crisis, it is an uncommon but potentially lethal condition. Patients with hypothyroidism may exhibit a number of physiologic alterations to compensate for the lack of thyroid hormone. If these homeostatic mechanisms are overwhelmed by factors such as infection, the patient may decompensate into myxedema coma. In correlation with this patient, initial symptoms of tremors, blank stares \& eventually leads in decreased 
in sensorium with concomitant community acquired pneumonia which was managed accordingly.

Myxedema coma is 4 - 8 times more common in women, such patient with an altered mental status, including lethargy, stupor, delirium, or coma. Secondary insults such as climate-induced hypothermia, infection, additional systemic conditions, or drug therapy can worsen the patient's condition [3].

In this patient, who is a diagnosed case of schizophrenia \& taking lithium for mood disorder but loss to follow up for years but continuously take the said drug. Chief complaint of tremor, primarily of the hands, is among the most common lithium side effects, seen in approximately one quarter of treated patients [4].

Lithium tremor is generally symmetric $\&$ is indistinguishable from essential or physiologic tremor. Lithium-induced tremor typically presents early in treatment but may emerge at any time. It is more common with older age, presumably due to the additive effects of age-related essential tremor. The type of lithium preparation does not alter tremor prevalence but higher lithium levels correlate with greater risk of tremor [5]. Lithium assay was done in this patient which showed moderately elevated (see Table 3 ).

Table 1. Thyroid function tests and lithium assay.

\begin{tabular}{ccc}
\hline & & Reference range \\
\hline Serum TSH & $57.16(\mathrm{H})$ & $0.25-4.00 \mathrm{uIU} / \mathrm{ml}$ \\
Serum fT4 & $1.71(\mathrm{~L})$ & $9.03-23.22 \mathrm{pmol} / \mathrm{l}$ \\
Lithium & $2.4 \mathrm{mmol} / \mathrm{l}(\mathrm{H})$ & $0.6-1.2 \mathrm{mmol} / \mathrm{l}$ \\
\hline
\end{tabular}

Table 2. Metabolic work up.

\begin{tabular}{ccc}
\hline CBC & & Reference range \\
\hline Hemoglobin & 118.0 & F: $120-160 \mathrm{~g} / \mathrm{L}$ \\
Hematocrit & 0.37 & F: $0.37-0.47$ \\
WBC & 13.3 & $5-10 \times 10^{9} / \mathrm{L}$ \\
Segmenter & 0.84 & $0.60-0.70$ \\
Lymphocyte & 0.15 & $0.20-0.40$ \\
Eosinophil & 0.01 & $0.01-0.05$ \\
Platelet & 196 & $150-450 \times 10^{9} / \mathrm{L}$ \\
Na & 138 & $136-145$ \\
K & 4.6 & $3.5-5.1$ \\
Creatinine & 153 & $44-80$ \\
ALT & 22 & $0-41$ \\
AST & 92 & $0-32$ \\
HBA1C & $9.30 \%$ & $<5.7 \%$ \\
\hline
\end{tabular}


Table 3. NCBI lithium Toxictiy categories.

\begin{tabular}{cc}
\hline MILD $(1.5 \mathrm{mEq} / \mathrm{L})$ & nausea, vomiting, lethargy, tremor \& fatigue \\
MODERATE $(2.5 \mathrm{mEq} / \mathrm{L})$ & confusion, agitation, delirium, tachycardia \& hypertonia \\
SEVERE $(3.5 \mathrm{mEq} / \mathrm{L})$ & Coma, seizures, hyperthermia, hypotension and death \\
\hline
\end{tabular}

This case is suspected of lithium-induced hypothyroidism symptoms are the same as seen in primary cases of the disorder. This includes lethargy, mental slowing, depression, weight gain, dry skin, \& cold intolerance. A number of these symptoms overlap with depression symptoms as well as side effects from lithium or other psychotropic agents, making diagnosis difficult in the absence of thyroid function tests [6].

\section{Lithium \& the thyroid}

To further discuss the effects of lithium with the thyroid. Lithium inhibits thyroid function at various points in the thyroid axis. A large number of studies have shown that anywhere from $0 \%$ to $47 \%$ of patients on long-term lithium treatment will develop clinical hypothyroidism [7].

Lithium has been shown to be highly concentrated in thyroid cells. Low thyroid iodine uptake could be due to lithium induced iodide retention \& competition for the iodide transport within the thyroid gland. An increase in the uptake could be mediated by the increased secretion of thyroid stimulating hormone (TSH) following lithium induced hypothyroidism [8].

Another key effect of lithium on thyroid gland functioning occurs at the level of hormone synthesis \& release. Lithium inhibits synthesis \& release of thyroid hormones. This inhibitory effect is due to the alteration in the tubulin polymerization \& inhibition of the action of TSH on cyclic adenosine mono phosphate (c-AMP). Lithium also alters the structure of thyroglobulin thereby affecting protein conformation \& function with subsequent iodotyrosine coupling defects. Lithium administration is associated with reduced hepatic deiodination \& clearance of free thyroxine $\left(\mathrm{T}_{4}\right)$. The latter induces a decrease in the activity of type I 5' deiodinase enzyme [8].

The etiology of lithium associated hypothyroidism \& subclinical hypothyroidism is primarily related to inhibition of synthesis \& release of thyroid hormones [5]. Other studies have demonstrated a transient lithium induced increase in titers of thyroid auto-antibodies (thyroid peroxidase auto-antibodies) present prior to lithium administration. No lithium induced production of thyroid auto-antibodies independently is thought to occur [9].

Myxedema Crisis \& Management

In diagnosing patient who is suspected to have myxedema coma immediate management is warranted. Myxedema coma is life-threatening condition resulting from severe hypothyroidism. It is characterized by decrease in sensorium, hypothermia, electrolyte derangements \& other symptoms related to hypothyroidism \& slowing of metabolic functions. It is a rare presentation of severe hypothyroidism, with an approximate incidence of 0.22 per million people per year 
in a previous European population study \& 1.08 per million people per year in a Japanese population study [10] [11]. Even with treatment, the mortality rate is high [10].

The American Thyroid Association recommends prompt initiation of treatment upon clinical diagnosis, without delay while waiting for blood test results. The treatment recommendation is a loading dose of intravenous levothyroxine at $200-400 \mathrm{ug}$ followed by a daily intravenous replacement dose of $75 \%$ of 1.6 $\mathrm{ug} / \mathrm{kg}$ [11]. However, the intravenous preparation of levothyroxine \& liothyronine are not locally available in the country. We therefore utilized the oral tablet preparation of levothyroxine, given via nasogastric tube at $100 \mathrm{mcg} / \mathrm{day}$. In a similar case, oral levothyroxine given as an oral loading dose of $400 \mathrm{mcg}$ followed by $100 \mathrm{mcg}$ daily dose was effective in the treatment of a patient with lithium intoxication-induced myxedema coma [12]. In addition, our patient was also given oral liothyronine. This was given since there is reduced conversion of thyroxine to triiodothyronine. The available preparation was $25 \mathrm{mcg}$ tablet \& patient was given at $12.5 \mathrm{mcg}$ (half tablet) every 8 hours. Other important therapeutic strategies done were fluid management \& electrolyte correction, antibiotic coverage for infection \& withdrawal of lithium.

\section{Conclusion}

In summary, this study presents a case of a 59-year old female, diagnosed with schizophrenia maintained on Lithium with unknown history of thyroid disease who presents with a decrease in sensorium \& tremors. Early recognition of myxedema coma is crucial, \& a high index of suspicion is typically warranted in the patients with signs of hypothyroidism, hypothermia, \& bradycardia. Treatment with thyroid hormone, steroids must be initiated as soon as possible without waiting for laboratory tests results.

\section{Recommendation}

Periodic thyroid function should be monitored before \& during lithium therapy $\&$ drug should be discontinued \& appropriate therapy instituted if hypothyroidism develops.

\section{Conflicts of Interest}

The authors declare no conflicts of interest.

\section{References}

[1] Chow, F. and Cockram, C. (1990) Thyroid Disorders Induced by Lithium and Amiodarone: An Overview. Adverse Drug Reactions and Acute Poisoning Reviews, 9, 207-222.

[2] Santiago, R. and Rashkin, M.C. (1990) Lithium Toxicity and Myxedema Coma in an Elderly Woman. The Journal of Emergency Medicine, 8, 63-66. https://doi.org/10.1016/0736-4679(90)90390-H

[3] Ahn, J., Kwon, H.-S., Ahn, H. and Sohn, Y. (2010) A Case of Myxedema Coma Pre- 
senting as a Brain Stem Infarct in a 74-Year-Old Korean Woman. Journal of Korean Medical Science, 25, 1394-1397. https://doi.org/10.3346/jkms.2010.25.9.1394

[4] Gorman, J., Kent, J., Sullivan, G. and Coplan, J. (2000) Neuroanatomical Hypothesis of Panic Disorder, Revised. The American Journal of Psychiatry, 157, 493-505.

[5] Vestergaard, P., Poulstrup, I. and Schou, M. (1988) Prospective Studies on a Lithium Cohort. 3. Tremor, Weight Gain, Diarrhea, Psychological Complaints. Acta Psychiatrica Scandinavica, 78, 434-441. https://doi.org/10.1111/j.1600-0447.1988.tb06363.x

[6] Gitlin, M. (2016) Lithium Side Effects and Toxicity: Prevalence and Management Strategies. International Journal of Bipolar Disorders, 4, Article No. 27. https://doi.org/10.1186/s40345-016-0068-y

[7] Coupland, N. (2008) Psychopharmacology for the Clinician Psychopharmacologie Pratique. Journal of Psychiatry and Neuroscience. 33. E1.

[8] Lazarus, J.H. (1998) The Effects of Lithium Therapy on Thyroid and ThyrotropinReleasing Hormone. Thyroid, 8, 909-913.

https://doi.org/10.1089/thy.1998.8.909

[9] Weetman, A.P., McGregor, A.M., Lazarus, J., Smith, B.R. and Hall, R. (1982) The Enhancement of Immunoglobulin Synthesis by Human Lymphocytes with Lithium. Clinical Immunology and Immunopathology, 22, 400-407.

https://doi.org/10.1016/0090-1229(82)90057-5

[10] Rodríguez, I., Fluiters, E., Perez-Mendez, L.F., Luna, R., Páramo, C. and García-Mayor, R.V. (2004). Factors Associated with Mortality of Patients with Myxoedema Coma: Prospective Study in 11 Cases Treated in a Single Institution. Journal of Endocrinology, 180, 347-350. https://doi.org/10.1677/joe.0.1800347

[11] Jonklaas, J., Bianco, A., Bauer, A., Burman, K., Cappola, A., Celi, F., Cooper, D., Kim, B., Peeters, R., Rosenthal, M.S. and Sawka, A. (2014) Guidelines for the Treatment of Hypothyroidism: Prepared by the American Thyroid Association Task Force on Thyroid Hormone Replacement. Thyroid, 24, 1670-1751. https://doi.org/10.1089/thy.2014.0028

[12] Ravindran, R. (2013) Drug Induced Oral Erythema Multiforme: A Case Report. Journal of Odontological Research, 1, 71-74. 